\title{
The esophagus as a working channel: successful closure of a large Mallory-Weiss tear with clips and an endoloop
}

A 56-year-old man with alcoholic liver disease presented to our unit with a 1-day history of hematemesis. On admission, his blood pressure was $100 / 60 \mathrm{mmHg}$ and pulse rate 102 beats/minute. The initial hematocrit was $29 \%$. Urgent esophagogastroduodenoscopy (EGD) revealed a large esophageal tear at the cardia, measuring $15 \times 10 \mathrm{~mm}$ ( Fig. 1). A diagnosis of Mallory-Weiss tear was made.

Placement of the clips seemed insufficient because of the large diameter and length of the tear. In order to bring together the edges of the tear, an endoloop (EndoLoop MAJ 254; Olympus, Tokyo, Japan) was inserted in the esophagus by the endoscope (Olympus EVIS EXERA II GIFH180) in a freehand manner. After the endoloop snare was correctly placed around the tear, the snare was anchored with four clips (Quickclip; Olympus) at the margins of the tear ( $\bullet$ Fig. $2 \mathrm{a}$ ).

The loop was then tightened to close the defect ( Fig. $\mathbf{2}$ b). The clinical course of the patient was uneventful, and followup EGD performed 4 weeks later revealed complete healing of the tear with formation of scar tissue ( $\bullet$ Fig. 3 ).

Application of clips and an endoloop in the esophagus has been described as a method for closure of large mucosal defects after endoscopic mucosal resection [1], and of esophagomediastinal fistulas [2]. The closure was completed with a single-channel endoscope in a sequential two-step maneuver: first, clips were deployed at the margins of the defect, followed by looping and tightening of the clips with the endoloop. A total of three patients were reported, with a $100 \%$ technical success.

In our case, the esophagus served as a second working channel, allowing us to apply both accessories simultaneously with a favorable outcome. Further studies will be required to prove the feasibility of this approach.

Endoscopy_UCTN_Code_TTT_1AO_2AI

Competing interests: None

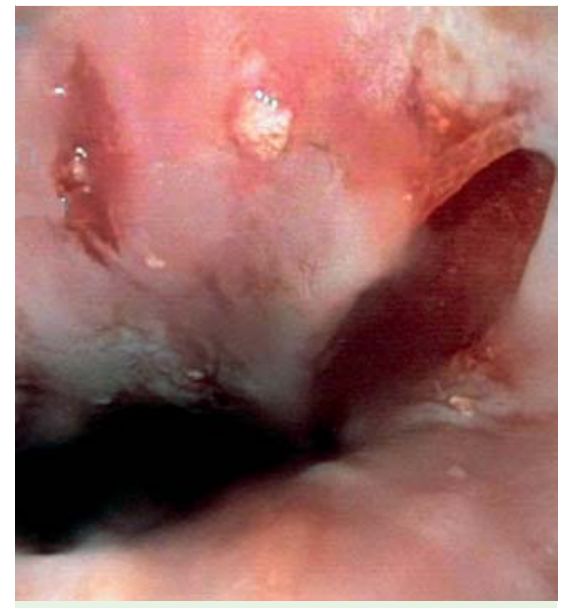

Fig. 1 A large esophageal tear at the cardia, seen at the index esophagogastroduodenoscopy (EGD).
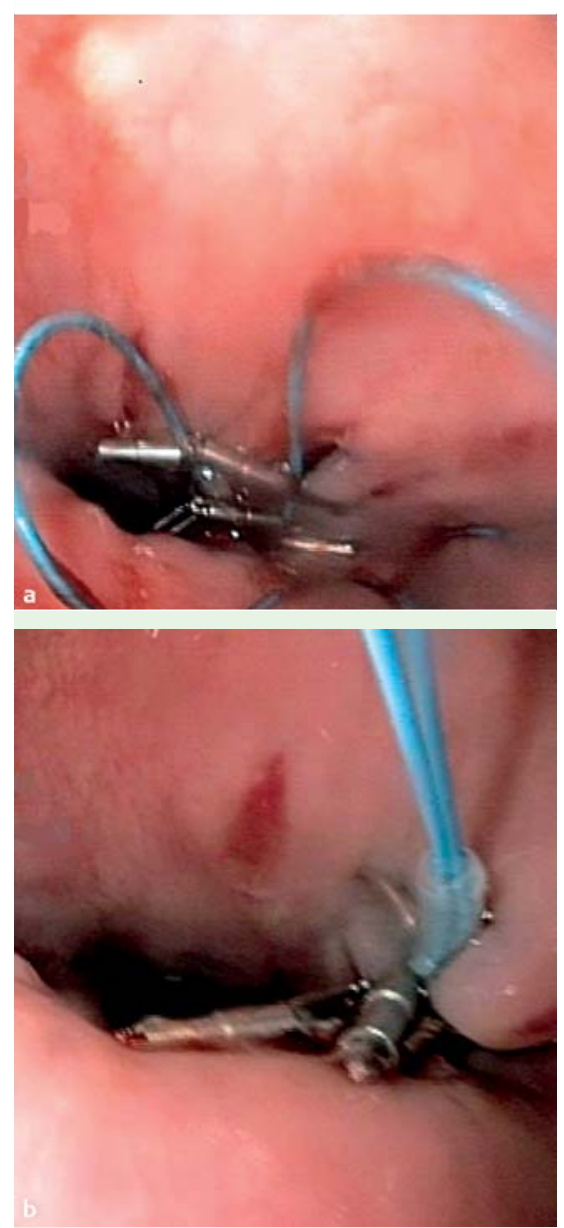

Fig. 2 An endoloop snare a anchored the margins of the tear, and $\mathbf{b}$ tightened.

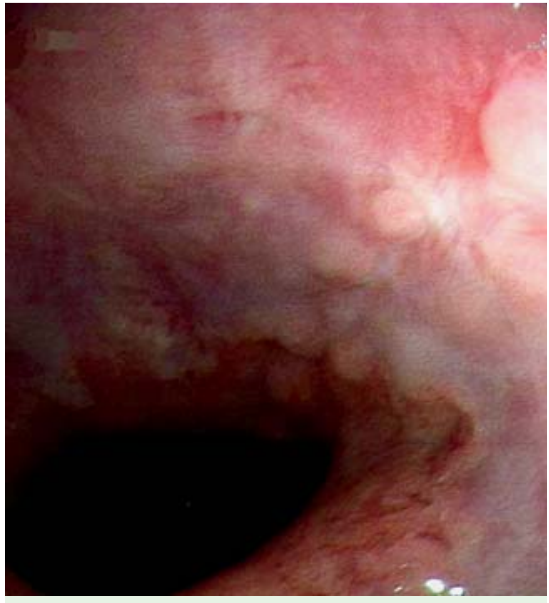

Fig. 3 Scar formation noticed at the follow-up esophagogastroduodenoscopy (EGD).

\section{H. Ivekovic, N. Rustemovic, T. Brkic, M. Opacic, R. Pulanic, R. Ostojic, B. Vucelic}

Department of Gastroenterology and Hepatology, University Hospital Zagreb, Croatia

\section{References}

1 Pouw R. "Tulip bundle technique" a novel technique for closing perforations caused by endoscopic resection, by placement of clips and approximation with endoloops. The DAVE Project 2010. Available from: http://daveproject.org/ViewFilms.cfm? Film_id=915 Accessed: 4 January 2011

2 Luigiano C, Ferrara F, Polifemo AM et al. Endoscopic closure of esophageal fistula using a novel "clips and loop" method. Endoscopy 2009; 41: E249-E450

Bibliography

DOI $10.1055 / \mathrm{s}-0030-1256273$

Endoscopy 2011; 43: E170

(c) Georg Thieme Verlag KG Stuttgart · New York . ISSN 0013-726X

\section{Corresponding author}

H. Ivekovic, MD

Department of Gastroenterology and Hepatology University Hospital Zagreb

Kispaticeva 12

Zagreb 10000

Croatia

Fax: +385-1-2388200

hrvoje.ivekovic@gmail.com 